\title{
DEMAND UNCERTAINTY, INVENTORY AND BUSINESS CYCLES
}

\author{
Kenichi TAMEGAWA \\ Faculty of Literature and Social Sciences, Yamagata University, 1-4-12, \\ Kojirakawa-machi, Yamagata-shi, Yamagata 990-8560, Japan \\ E-mail: tamegawa@human.kj.yamagata-u.ac.jp \\ Received 14 June 2013; accepted 07 August 2014
}

\begin{abstract}
This paper introduces demand uncertainty and inventory into a dynamic stochastic general equilibrium model. We assume that firms must predict demand before production. The purpose of this study is to investigate the effects of several exogenous shocks on the model economy in our settings. A numerical simulation using our model shows the following results. When shocks that raise expected demand are given, inventory stocks increase because output exceeds demand. In the next period, firms release the inventory stock, reducing excess stock and decreasing output. Thus, inventory adjustment causes recession. This result implies that cyclical movement (economic boom and bust) continues until variables return to the steady state. Furthermore, we confirm that our model can reproduce stylized facts for inventory movements and enhance empirical fit relative to the model without inventory.
\end{abstract}

Keywords: demand uncertainty, DSGE modeling, inventory, business cycles, production smoothing, simulation analysis.

JEL Classification: E32, E52, E62.

\section{Introduction}

Economists often use variants of the Real Business Cycle (RBC) model introduced by Kydland and Prescott (1982) to explain business cycles. This RBC model, with its various assumptions of market frictions (for example, price rigidity), has become a standard tool in macroeconomic analysis. Such models are called Dynamic Stochastic General Equilibrium (DSGE) models.

In the actual economy, firms face demand uncertainty and therefore have to predict the demand for their goods before production. These predictions form the basis of the firms' shipment decisions. With such demand uncertainty, inventory stock needs to be incorporated into the model to equalize the actual demand with sales. Therefore, differences between actual demand and output plus shipment can be compensated by inventory. Incorporating inventory is also a crucial feature of the proposed model because relatively few DSGE models consider the movement of inventory stock, which is an important element for the business cycle. As Blinder and Maccini (1991) pointed out, 
$87 \%$ of the decrease in the GDP of the United States after World War II was explained by changes in inventory stock in the economy. Thus, incorporating inventory stocks into DSGE modeling for a more accurate understanding of business cycles is vital. Our aim is to (1) incorporate inventory resulting from demand uncertainty into a DSGE model, (2) assess its business cycle implications, and (3) show the validity of the model.

This paper is organized as follows. Section 1 briefly reviews related literature. Section 2 discusses the relationship between inventory stock and output in detail. In Section 3, we explain the behavior of each economic agent that forms part of our general equilibrium model. In Section 4, we formulate the process of demand prediction commonly used by firms. After we set the parameters in Section 5, we implement a numerical simulation to investigate how our model reacts to exogenous shocks in Section 6. Section 7 discusses the applicability of our model to the actual economy. Finally, the last presents the conclusions and findings of this paper.

\section{Related literature}

A production-smoothing hypothesis can be used as a classical analytical framework for inventory movements. As an analytical framework of inventory movements, a production-smoothing hypothesis can be used as a classical tool. This hypothesis states that firms have an incentive to hold inventory if they can reduce production cost by doing so. However, the empirical results of many studies tend to reject this hypothesis (see Blanchard 1983; Blinder, Maccini 1991). These studies attempt to avoid drawbacks related to inventory by using means other than a production-smoothing model. For example, Blanchard (1983) and Khan (1987) assume firms' stockout-avoiding motive. Similarly, Blinder (1986) and Ramey (1991) assume cost shocks and non-convex production costs, respectively. Bils and Khan (2000) construct the model that inventories have a direct effect on sales. Furthermore, Blinder (1981) and Caplin (1985) use the (S, s) model to investigate the relationship between inventory and production ${ }^{1}$. Wen (2005) has pointed out that the model advocated by Kahn (1987) is consistent with actual data from the U.S. and other OECD countries. In contrast, Khan and Thomas (2007b) show that the $(\mathrm{S}, \mathrm{s})$ model can explain the average size of inventories in the U.S. data.

More recently, Wang et al. (2014) introduce a tractable approach to incorporating the (S, s) policy into DSGE models. Auernheimer and Trupkin (2014) use a DSGE model with inventories to investigate properties of capital utilization in U.S. cyclical fluctuations. Alessandria et al. (2013) attribute some fraction of persistent fluctuations in international trade to the decisions of importers for inventory holdings. Teo (2011) investigates how the optimal monetary policy depends on inventory in a New Keynesian small open model.

While the above literature adopted a partial equilibrium approach, this paper investigates the effects of various exogenous shocks in a DSGE framework. Recall that we

\footnotetext{
${ }^{1}$ In the (S, s) model, if inventory stock for a firm is below a certain level (typically denoted by s), the firm orders inventory up to a certain maximum level (denoted by S). For details, see Stokey and Lucas (1989).
} 
assume firms cannot observe demand before production activity and thus must predict the demand. By introducing these assumptions, we obtain interesting results on business cycles. As the main contributions of this paper, we (1) incorporate inventory into a DSGE model in a tractable manner and (2) show a system for demand prediction in which the model can reproduce two periodic business cycles (two pairs of an economic boom and a recession) that result from inventory movements only by a one-time exogenous shock ${ }^{2}$. The latter is explained as follows: when a shock that raises expected demand is given, inventory stocks increase because firms produce more than the demand under some manner of demand prediction. Next, the firms release this inventory stock to reduce their output excess. Such an inventory adjustment causes recession and the business cycle continues until the excess inventory stock has been eliminated. In addition to this result, we find that an observed relationship between output and inventory, which is explained in Section 2, can be generated using our model. These findings have not been identified by the existing literature on DSGE models with inventory (e.g., Christiano 1988; Fisher, Hornstein 2000; Khan, Thomas 2007a, 2007b) ${ }^{3}$. Furthermore, we find that our model can reproduce stylized facts for inventory literature: excess volatility of output with respect to sales and positive correlation between output and inventory investment.

\section{Inventory and business cycles}

In this section, we briefly consider the relationship between inventory and business cycles. To do this, a figure such as Figure 1 is useful; such figures are often used among practical economists. This figure is a scatter graph in which the vertical axis plots the rate of change of output (or shipment) and the horizontal axis shows the rate of change of inventory stock. In this figure, the inventory cycle is drawn in a counterclockwise curve. The cycle can be explained by dividing it into four phases: Phase I, in which firms observe an unintentional decrease in inventory; Phase II, in which firms intentionally increase inventory and output; Phase III, in which firms observe an unintentional increase in inventory; and Phase IV, in which firms intentionally decrease inventory and output. A detailed explanation of each phase follows. At first, it is assumed that the firm observes a sudden decrease in its inventory (Phase I), thereby recognizing the existence of an unexpected inventory change. This allows firms to begin to increase output and inventory before a possible increase in demand (Phase II). As the increase in output exceeds the increase in demand, the inventory stock rises (Phase III), and the firm begins to decrease its production intentionally (Phase IV), causing an economic recession. Therefore, by identifying which phase the economy is currently in, we can forecast output movement. Figure 1 visualizes such an inventory cycle.

\footnotetext{
${ }^{2}$ Lubik and Teo (2012) incorporate inventories into a standard New Keynesian model and study the inflation dynamics.

${ }^{3}$ Zeira (1994) pointed out that production and investment cycles resulted from a firm's predictions of its demand and subsequent updates based on new information. He implemented a simple general equilibrium analysis in addition to a partial equilibrium analysis. Beaudry and Portier (2004a, 2004b) showed that an expectation shock can generate an economic boom and recession.
} 
For the purpose of this paper, we construct a sample inventory cycle from U.S. economic data. Figure 2 is a scatter graph of the output and inventory based on these data. On the assumption that the inventory cycle is a short-run phenomenon, long-run variations have been removed by the Hodrick-Prescott filter. Thus, from Figure 2 we can confirm that business cycles are caused by inventory adjustments.

The figure also sheds light on the correlation of output and inventory investment, that is, whether the correlation might be positive or negative. Wen (2005) reports that the correlation is positive at a low-cyclical and negative at a high-cyclical frequency. The fact that the calculated correlation, which is 0.5 in our data, is positive reflects the large positive correlation at a low-cyclical frequency.

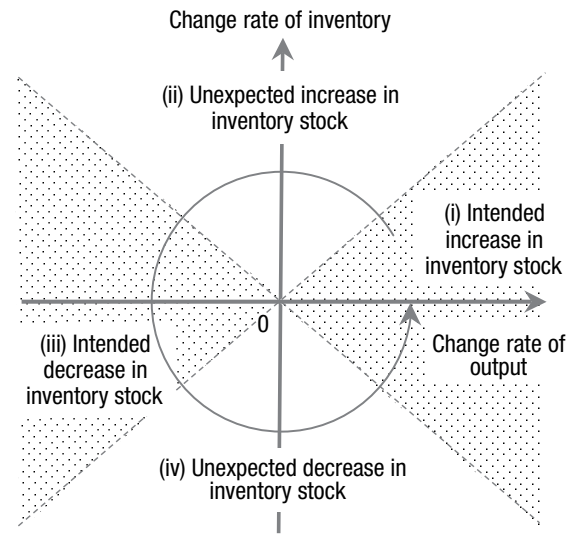

Fig. 1. Inventory cycle

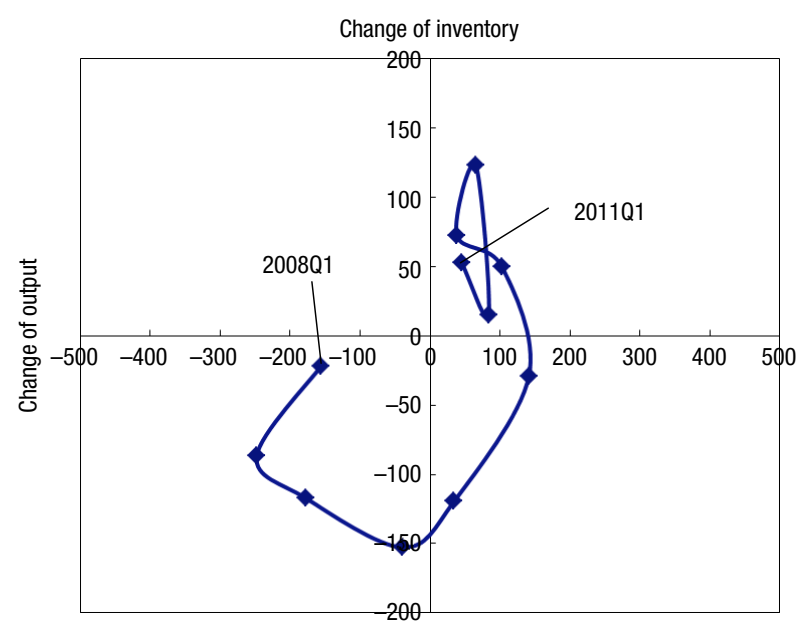

Fig. 2. Inventory cycle: change of inventory

Notes: Data (billions of chained (2005) dollars) has been detrended by the Hodrick-Prescott filter. The change in output is the current cyclical real GDP minus the previous cyclical GDP. The change in inventory is the cyclical change in real private inventories.

Source: Bureau of Economic Analysis. 


\section{The model}

In this section, we construct a new Keynesian type of DSGE model because the inventory cycle appears to be a short-term phenomenon. In the model, there are retail firms, wholesale firms, households, the government, and the central bank. The retail firms purchase wholesale goods from the wholesale firms and sell them as final goods to the final goods demand source under a sticky pricing mechanism.

\subsection{Wholesale firms}

We assume homogeneous wholesale firms operating under perfect competition. They plan to manage their shipment (= output minus inventory investment) for wholesale goods in a manner that maximizes profits. Furthermore, it is assumed that wholesale firms cannot observe their current demand, $Y_{t}^{d}$, before production activity. Hence, this type of demand uncertainty forces firms to predict demand at the planning stage of their shipment. An explanation as to how wholesale firms predict demand is provided in Section 4. Returning to the demand conditions mentioned above, we implement the output $Y_{t}$, inventory release $b_{t}^{4}$, and shipments $\left(Y_{t}+b_{t}\right)$, denoting the predicted demand as $Y_{t}^{d, e}$, such that the firms satisfy the following equation:

$$
Y_{t}^{d, e}=Y_{t}+b_{t} \text {. }
$$

Note that $b_{t}<0$ indicates an inventory investment. We assume the following CobbDouglas-type production function:

$$
Y_{t}=e^{A_{t}} K_{t}^{\alpha}\left(L_{t} H_{t}\right)^{1-\alpha},
$$

where $L_{t} H_{t}$ refers to man-hours ( $L_{t}$ represents labor force and $H_{t}$ the hours worked), $K_{t}$ is capital stock, and $A_{t}$ the technology shock. We assume $A_{t}=\rho^{y} A_{t-1}+\varepsilon_{t}^{Y}$, where $\varepsilon_{t}^{Y}$ is a random variable with a mean of one. Further, capital stock is accumulated according to the following equation:

$$
K_{t+1}=(1-\delta) K_{t}+I_{t},
$$

where $\delta$ is the capital depreciation and $I_{t}$ the capital investment. In this paper, $b_{t}$ is a choice variable and, therefore, $Y_{t}^{d} \neq Y_{t}^{d, e}$ because of demand uncertainty. With this in mind, inventory stock $N_{t}$ is accumulated as follows:

$$
N_{t+1}=N_{t}-b_{t}+z_{t}
$$

where $z_{t}$ denotes an "unexpected" inventory change. Wholesale firms take this change as an i.i.d. random variable with mean 0 , while in a general equilibrium, an unexpected inventory change is expressed as:

$$
z_{t}=Y_{t}+b_{t}-Y_{t}^{d}
$$

We now explain the cost structure. The firms pay real wage rate $w_{t}$ per man-hour. Hence, the labor cost is expressed by $w_{t} L_{t} H_{t}$. In addition, we assume that firms have

\footnotetext{
${ }^{4}$ Note that $b_{t}$ is a control variable.
} 
to pay costs of capital $\Phi\left(I_{t} / I_{t-1}\right) I_{t}$ to install investment $I_{t}$, holding costs of inventory stock $f\left(N_{t}\right)$, and costs of inventory adjustment $g\left(b_{t}\right)$. Intuitively, $f\left(N_{t}\right)$ expresses the cost of freezing, and $g\left(b_{t}\right)$, that of thawing the food (if $b_{t}>0$ ). Introducing $g\left(b_{t}\right)$ forces firms to hold inventory stock. We assume that these adjustment costs are paid to the investment installers and inventory management firms. For the later simulation, we assume the following parametric forms for the above-mentioned costs:

$$
\begin{gathered}
\Phi\left(\frac{I_{t}}{I_{t-1}}\right) \equiv \frac{\chi}{2}\left(e^{\varphi_{t}} \frac{I_{t}}{I_{t-1}}-1\right)^{2}, \\
f\left(N_{t}\right) \equiv \gamma_{1} N_{t}^{2} / 2, \\
g\left(b_{t}\right) \equiv \gamma_{2} b_{t}^{2} / 2+\gamma_{3} b_{t}+\gamma_{4}, \\
\gamma_{i}>0, i=1,2,3,4, \varphi_{t}=\rho^{I} \varphi_{t-1}+\varepsilon_{t}^{I},
\end{gathered}
$$

where $\varphi_{t}$ in Eq (6) represents an investment technology shock and $\varepsilon_{t}^{I}$ is an i.i.d. shock with mean 0. Eq. (6) has been used by Christiano et al. (2005). In this function, capital stock is adjusted gradually. It has been frequently used to raise the fit to the actual economy in many papers. Note that we need $\gamma_{3}$ to allow for zero inventory release in the steady state and $\gamma_{4}$ to obtain $g\left(b_{t}\right)>0$ for all $b_{t}$.

With these assumptions, we can write the profit function as follows:

$$
\frac{P_{t}^{w}}{P_{t}}\left(Y_{t}^{d, e}-z_{t}\right)-f\left(N_{t}\right)-g\left(b_{t}\right)-g\left(z_{t}\right)-w_{t} L_{t} H_{t}-I_{t}-\Phi\left(\frac{I_{t}}{I_{t-1}}\right) I_{t},
$$

where $P_{t}$ and $P_{t}^{w}$ are the final goods price and wholesale goods price, respectively. The firms choose their factor demand in a manner that maximizes the above profits.

From the above settings, at date 0 , the firms choose $\left\{I_{t}\right\},\left\{b_{t}\right\}$, and $\left\{H_{t}\right\}$ to maximize their present value of profits given sequences of the wholesale price, final goods price, and factor prices:

$$
\begin{gathered}
\max _{\left\{I_{t}\right\},\left\{b_{t}\right\},\left\{H_{t}\right\}} E_{0} \sum_{t=0}^{\infty} \beta_{t}\left[\frac{P_{t}^{w}}{P_{t}}\left(Y_{t}+b_{t}\right)-f\left(N_{t}\right)-g\left(b_{t}\right)-g\left(z_{t}\right)-w_{t} L_{t} H_{t}-I_{t}-\Phi\left(\frac{I_{t}}{I_{t-1}}\right) I_{t}\right], \\
\text { s.t. } K_{t+1}=(1-\delta) K_{t}+I_{t}, \\
N_{t+1}=N_{t}-b_{t}+z_{t}, \\
Y_{t}=A_{t} K_{t}^{\alpha}\left(L_{t} H_{t}\right)^{1-\alpha}, \\
\beta_{t}=\prod_{j=1}^{t} R_{j}^{-1}, \beta_{0}=1,
\end{gathered}
$$

where $\beta_{t}$ is the discount factor and $R_{t}$ the real interest rate, defined as $R_{t}=P_{t-1} R_{t}^{n} / P_{t}$, where $R_{t}^{n}$ denotes the nominal interest rate. Note that we allow the backlog mainly for analytical simplicity.

Let $q_{t}$ and $\mu_{t}$ be the Lagrange multipliers for capital stock and inventory stock, respectively. Then, the first-order conditions for the above problem are as follows: 


$$
\begin{gathered}
-q_{t}+E_{t}\left[R_{t+1}^{-1}\left(\alpha \frac{Y_{\mathrm{t}+1}}{X_{t+1} K_{t+1}}+q_{t+1}(1-\delta)\right]=0\right. \\
-1-\left[\Phi^{\prime}\left(\frac{I_{t}}{I_{t-1}}\right) \frac{I_{t}}{I_{t-1}}+\Phi\left(\frac{I_{t}}{I_{t-1}}\right)\right]+q_{t}+E_{t}\left[R_{t+1}^{-1} \Phi^{\prime}\left(\frac{I_{t+1}}{I_{t}}\right)\left(\frac{I_{t+1}}{I_{t}}\right)^{2}\right]=0 \\
w_{t} L_{t}=(1-\alpha) \frac{Y_{\mathrm{t}}}{X_{t} H_{t}} \\
\frac{1}{X_{t}}-\left(\gamma_{2} b_{t}+\gamma_{3}\right)-\mu_{t}=0 \\
-\mu_{t}+E_{t}\left[R_{t+1}^{-1}\left(\mu_{t+1}-\gamma_{1} N_{t+1}\right)\right]=0
\end{gathered}
$$

where $X_{t}=P_{t} / P_{t}^{w 5}$. These conditions are briefly explained as follows. Eq. (9) states that $q_{t}$, which is interpreted as the marginal $q$, is equal to the discounted present value of marginal profits of capital. Eq. (10) says capital investment depends on the discounted present value of the marginal $q$. Eq. (11) states that labor is demanded such that the real wage rate is equal to the marginal productivity of labor. Both Eqs. (12) and (13) show how the firms control inventory investment. The inventory movement is briefly explained as follows. Using Eqs. (7) and (8), we can rearrange Eqs. (12) and (13) as:

$$
\begin{gathered}
b_{t}=\frac{1}{\gamma_{2} \Gamma}\left(\frac{1}{X_{t}}-\mu_{t}-\gamma_{3}\right), \\
\mu_{t}=-E_{t}\left[\sum_{i=1}^{\infty}\left(\beta_{t+i}\right)^{-i}\left(\gamma_{1} N_{t+i}\right)\right] .
\end{gathered}
$$

These equations imply that a large inventory stock at the beginning of the period forces firms to increase the release of inventory stock. Moreover, $b_{t}$ depends negatively on the shadow value of inventory stock $b_{t} \mu_{t}$, which is equal to the negative of the discounted present value of marginal cost of holding inventory, as shown in Eq. (15). $b_{t}$ also depends negatively on $X_{t}$. Note, that $X_{t}$ decreases if an economic boom occurs. This is because wholesale goods prices are more flexible than their final goods prices ${ }^{6}$. Hence, the firms increase the release of inventory stock against an economic boom. Thus, the firms adjust inventory stock to smooth production.

We incorporate inventory as above for analytical tractability, although an alternative motive for maintaining inventory, such as the $(\mathrm{S}, \mathrm{s})$ motive or the stockout avoidance motive, can be considered. As shown in Section 7, our model, though simple, can reproduce stylized facts for inventory theory.

\footnotetext{
${ }^{5} X_{t}$ can be interpreted as the markup ratio for retailers.

${ }^{6}$ For further details, see Subsection 3.6.
} 


\subsection{Retailers}

In this paper, we assume that retailers are in monopolistic competition and are unable to change their selling prices with probability $\theta$ (also see Calvo 1983), as in many standard new Keynesian models. Under these assumptions, the retail firm $i \in[0,1]$ behaves in such a manner as to maximize the present value of its profit as follows:

$$
\max _{p_{t}} E_{t} \sum_{j=0}^{\infty}\left(R_{t+j}\right)^{-j} \theta^{j}\left(\frac{p_{i, t}^{*}}{P_{t+j}}-\frac{1}{X_{t+j}}\right) Y_{i, t+j}^{*},
$$

where $Y_{i, t+j}^{*} \equiv\left(p_{i, t+j}^{*} / P_{t+j}\right)^{-\phi} Y_{t+j}^{d}(\phi>1)$ represents the demand function for retailers, where $Y_{t}^{d}$ refers to the aggregate demand and $p_{t}^{*}$ shows the final goods price optimally set by retailers who are able to change their prices. The corresponding price index is given as follows:

$$
P_{t}=\left(\int_{0}^{1} p_{i, t}^{1-\phi} d i\right)^{1 /(1-\phi)} .
$$

On the assumption that all retailers are homogenous, $p_{i, t}^{*}$ will be the same for all of them. If this level is $p_{t}^{*}$, the following equation is obtained:

$$
P_{t}=\left\{\theta P_{t-1}^{1-\phi}+(1-\theta)\left(p_{t}^{*}\right)^{1-\phi}\right\}^{1 /(1-\phi)} .
$$

From this equation and the first-order condition for setting up the optimal price, the new Keynesian Phillips curve (NKPC) is expressed as:

$$
\begin{aligned}
& \hat{\pi}_{t}+\kappa \hat{X}_{t}-\beta E_{t}\left(\hat{\pi}_{t+1}\right)=0, \\
& \kappa \equiv \frac{(1-\theta)(1-\theta \beta)}{\theta} .
\end{aligned}
$$

In this equation, “^” indicates the deviation rate from the steady state ( $\hat{\pi}_{t}$ is a deviation gap; that is, $\left.\hat{\pi}_{t} \equiv \hat{P}_{t}-\hat{P}_{t-1}\right)$. For this reason, the final goods price moves sluggishly in contrast to the flexible movement of the wholesale goods price.

\subsection{Households}

On the assumption that households are homogenous, their aggregated budget constraint is defined as follows:

$$
\frac{D_{t+1}}{P_{t}}=\frac{R_{t}^{n}}{P_{t}} D_{t}+\Pi_{t}+w_{t} L_{t} H_{t}-C_{t}-T_{t},
$$

where $C_{t}$ represents consumption at the time $t, D_{t}$ is the nominal deposit at the beginning of time $t$, and $T_{t}$ is the lump-sum tax at time $t$. $R_{t-1}^{n}$ is the nominal deposit interest rate, which is predetermined at the beginning of period $t . \Pi_{t}$ represents the aggregate earnings from profits from the various firms (wholesale firms, retailers, investment installers, and inventory management firms). With this budget constraint and given the 
no-Ponzi Game (NPG) condition, households maximize their inter-temporal utility. In this paper, we assume that our temporal utility function is dependent on both current and past consumption. Given this, we use a temporal utility function of $\log \left(C_{t}-b C_{t-1}\right)^{7}$. In addition, our model assumes an additive disutility emerging from households' labor. Under these assumptions, households' maximization problem can be expressed as:

$$
\begin{aligned}
\max _{\left\{C_{t}\right\},\left\{H_{t}\right\}} E_{t} \sum_{t=0}^{\infty} \beta^{t}\left[\log \left(C_{t}-\Psi C_{t-1}\right)+\mathrm{t} \log \left(1-H_{t}\right)\right], \\
\text { s.t. } \frac{D_{t+1}}{P_{t}}=\frac{R_{t}^{n}}{P_{t}} D_{t}+\Pi_{t}+w_{t} L_{t} H_{t}-C_{t}-T_{t}, \\
\lim _{t \rightarrow \infty} D_{t}\left(R_{t}^{n}\right)^{-t}=0,
\end{aligned}
$$

where the time available for households is normalized to 1 and $1-H_{t}$ represents the leisure time consumed by households. The second constraint is the NPG condition. The first-order conditions are expressed as follows:

$$
\begin{gathered}
\frac{1}{C_{t}-\Psi C_{t-1}}-\beta b E_{t}\left[\frac{1}{C_{t+1}-\Psi C_{t}}\right], \\
-\beta E_{t}\left[\frac{\beta b R_{t+1}^{n}}{\left(C_{t+1}-\Psi C_{t}\right)\left(P_{t+1} / P_{t}\right)}-\frac{1}{\left(C_{t+2}-\Psi C_{t+1}\right)\left(P_{t+1} / P_{t}\right)}\right], \\
w_{t} L_{t}\left(\frac{1}{C_{t}-\Psi C_{t-1}}-\beta b E_{t}\left[\frac{1}{C_{t+1}-\Psi C_{t}}\right]\right)=\mathrm{t} \frac{1}{1-H_{t}} .
\end{gathered}
$$

Eq. (18) is the Euler equation for habit formation, while Eq. (19) describes the labor supply function ${ }^{8}$.

\subsection{Government}

The government collects a lump-sum tax from households and spends the tax revenue as government expenditures, given as $G_{t}$. We assume that the government issues government bonds if it is unable to finance its expenditure $\left(G_{t}\right)$. We also assume that the following process determines government expenditure:

$$
G_{t}=\text { const. } \times e^{\varepsilon_{t}^{G}}\left(G_{t-1}\right)^{\rho^{G}}
$$

where $\varepsilon_{t}^{G}$ is a random variable with a mean of 0 .

\footnotetext{
${ }^{7}$ Many of the recent research papers that employ the DSGE model adopt the assumptions of habit formation. See also Christiano et al. (2005), Smets and Wouters (2007).

${ }^{8}$ We employ "internal" rather than "external" habit formation. In Nutahara (2010), internal habit is needed for the co-movement between consumption and labor in a news shock for productivity.
} 


\subsection{Central bank}

The central bank sets nominal interest rates as follows:

$$
R_{t}^{n}=\text { const. } \times e^{\varepsilon_{t}^{R}}\left(R_{t-1}^{n}\right)^{\xi_{R}}\left\{\left(P_{t} / P_{t-1}\right)^{\xi_{\pi}}\left(Y_{t} / Y\right)^{\xi_{\pi}}\right\}^{1-\xi_{R}},
$$

where $\varepsilon_{t}^{R}$ is a random variable with mean 0 and $Y$ is the steady-state value of output.

\subsection{General equilibrium}

Equilibrium in the labor market is determined with Eqs. (11) and (19). The equilibrium in the final goods market is expressed as follows:

$$
Y_{t}+b_{t}=C_{t}+I_{t}+G_{t}+z_{t}
$$

Note, that since wholesale firms' decisions regarding production of goods and release of inventories are taken before their demand is revealed, the labor market is also cleared at this stage. The above condition is used to pin down "unexpected" inventories $z_{t}$.

\section{Prediction of demand}

In this section, we explain how wholesale firms predict demand. This paper assumes that wholesale firms cannot observe demand before making their production decision. Therefore, in our model, the wholesale firms have to decide their actions before they can observe their demand ${ }^{9}$. This implies that they have to predict demand based on the available information. We assume that the firms' demand prediction can be calculated as follows:

$$
Y_{t}^{d, e}=\varepsilon_{t}^{d} E_{t-1}\left[Y_{t}^{d}\right]
$$

In this equation, $\varepsilon_{t}^{d}$ is the shock that affects demand prediction, and it can be interpreted as a news shock for current demand. This formulation can be interpreted as a situation in which the firms face "sticky information".

While we can simply assume that $\left\{\varepsilon_{t}^{d}\right\}$ is an i.i.d. random variable, we also assume that its conditional expectation depends on economic information. As a natural candidate for this, we can consider the index of a business cycle such as the ISM manufacturing report on business. In this paper, we simply assume the following:

$$
\varepsilon_{t}^{d}=e^{\varepsilon_{t}^{n}}\left(Y_{t-1} / Y\right)^{\sigma}
$$

where $\varepsilon_{t}^{n}$ is a random variable with a mean of 0 . The parameter $\sigma$ in Eq. (22) expresses the "attitude" for momentum in the economy. In the case of $\sigma>0$, if the previous pe-

\footnotetext{
${ }^{9}$ The details of wholesale firms' behavior are as follows. To get the intuition, we abstract from capital stock. First, wholesale firms optimally choose their production schedule and inventory release schedule before their demand is observed, as explained in Section 3. Next, they hire labor on the basis of their demand prediction. Finally, the labor market is cleared such that $Y_{t}^{d, e}=Y_{t}+b_{t}$. Note that the difference between actual demand and demand prediction is compensated by unexpected inventory in general equilibrium; that is, $z_{t}=Y_{t}^{d, e}-Y_{t}^{d}$, as explained in Subsection 3.6.
} 
riod's output was large (small), firms predict that the current period's demand will also be large (small). On the other hand, in the case of $\sigma<0$, if the previous period's output was large (small), firms predict that the current period's demand will be small (large). In particular, the case of $\sigma>0$ is interesting because it depicts an attitude in which agents form optimistic expectations in an economic boom and pessimistic expectations in an economic recession.

\section{Parameter setting}

The model constructed above is linearized around the steady state to obtain the reduced form. To do this, we set our model's parameters as shown in Table 1. Specifically, we set the discount factor $(\beta)$ at 0.99 , the capital depreciation rate $(\delta)$ at 0.02 , and the capital share rate $(\alpha)$ at $1 / 3$. If the probability of a change in the retailer's price is assumed to be $0.25, \kappa$ in NKPC will stand at 0.08 . The adjustment cost parameter for capital investment is set at 3.24, which is borrowed from Christiano et al. (2005). The parameters for the central bank's interest rate rules are standard: $\xi_{R}=0.9, \xi_{Y}=0.1$, and $\xi_{\pi}=1.1$. We set the steady-state value of $H_{t}$ at $1 / 3$. The steady-state value of markup rate $X_{t}$ is set at 1.1. The habit parameter for consumption $b$ is set at $0.8 . \gamma_{1}, \gamma_{2}$, and $\gamma_{3}$, which characterize the inventory holding cost and the inventory adjustment cost are set at $\gamma_{1}=10$, $\gamma_{2}=10$, and $\gamma_{3}$ such that it yields $N=b=0$, where $X, N$, and $b$ are the steady-state values of $X_{t}, N_{t}$, and $b_{t}$, respectively. By normalizing output, we set $Y=1$. Finally, we set $\rho^{Y}=\rho^{I}=\rho^{G}=0.9$.

Table1. Parameter settings

\begin{tabular}{ccl}
\hline$\beta$ & 0.99 & Discount rate \\
\hline$H$ & $1 / 3$ & Hours worked \\
\hline $1-\theta$ & 0.25 & Probablity of price change \\
\hline$\gamma_{1}$ & 10 & Holding cost of inventory \\
\hline$\gamma_{2}$ & 10 & Adjustment cost of inventory \\
\hline$\xi_{R}$ & 0.90 & Persistency parameter in interest rate rule \\
\hline$\xi_{\pi}$ & 1.50 & Response to inflation in interest rate rule \\
\hline$\xi_{Y}$ & 0.10 & Response to output gap in interest rate rule \\
\hline$\alpha$ & $1 / 3$ & Capital share \\
\hline$X$ & 1.10 & Markup ratio \\
\hline$\Psi$ & 0.80 & Parameter for habit \\
\hline$\rho^{Y}$ & 0.90 & Persistency parameter for productivity shock \\
\hline$\rho^{G}$ & 0.90 & Persistency parameter for fiscal shock \\
\hline$\rho^{I}$ & 0.90 & Persistency parameter for investment technology shock \\
\hline$\delta$ & 0.02 & Depreciation rate \\
\hline
\end{tabular}




\section{Simulation analysis}

In this section, we present the results of our simulation analysis using the linearized model.

\subsection{Impulse responses}

In this subsection, we show how our model responds to the demand prediction shock $\left(\varepsilon_{t}^{n}\right)$ and the productivity shock $\left(\varepsilon_{t}^{Y}\right)$.

In each simulation, we consider the following two cases: $\sigma=2$ (Case I) and $\sigma=0$ (Case II), as included in Eq. (22).

(a) Demand prediction shock

Figure 3 shows the impulse responses to a $1 \%$ shock in $\varepsilon_{t}^{n}$. The solid line and the marked line show the impulse responses in Case I and Case II, respectively. In both cases, we can state that the output increases in the first period. This is because the firms' demand prediction is revised upward. The increase in output needs the associated increase in hours worked. This is done by the upward shift of the labor demand curve through decreases in the markup ratio $X_{t}$.

Since the actual demand does not increase as the firms expect it to, the inventory stock rises through an increase in the unexpected inventory. Therefore, the firms decrease output to cut their inventory stock during Period 2. This leads to an economic recession because of an inventory adjustment. Then in Case I, because the firms predict that demand is lower than necessary, the unexpected inventory stock decreases. The firms increase output in response, leading to the second business cycle, although this cycle is small. On the other hand, in Case II, the business cycle occurs just once because the firms do not make volatile predictions.

The above boom and bust can be observed after the prediction shock is revealed. During Period 1, the recession continues over several periods, leading economic agents to expect the central bank to decrease the nominal interest rate according to the interest rate rule. In this way, consumption and investment rise. In our model, consumption and investment is more persistent because we assume habit formation and an adjustment cost function of the Christiano et al. (2005) type.

\section{(b) Productivity shock}

Next, we consider the effects of a productivity shock. Figure 4 shows the impulse responses to a $1 \%$ shock in $\varepsilon_{t}^{Y}$. As shown in the figure, demand increases in the first period for both Case I and Case II. Investment increases through a rise in the marginal $q$. Consumption also increases because a rise in productivity leads households to expect an increase in their permanent income. As demand increases, the firms produce more output than necessary, except in the first and second periods. This leads to an increase in inventory stock while the increase in output slows down.

An interesting feature of our model is that the response of the variables is hump-shaped. This is because the firms cannot observe the increase in demand and therefore cannot expand output in the first period. The increase in demand is compensated by a decrease in inventory stock. In the second period, the firms expect this period's demand to increase, so they increase output. 


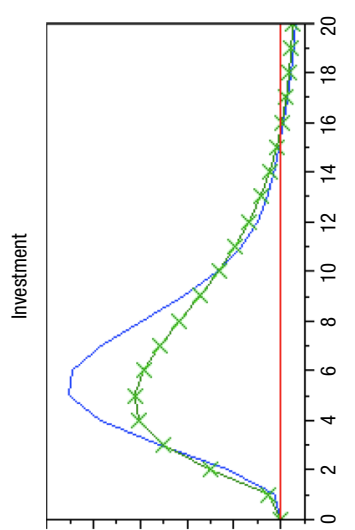

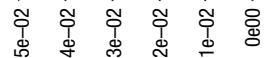
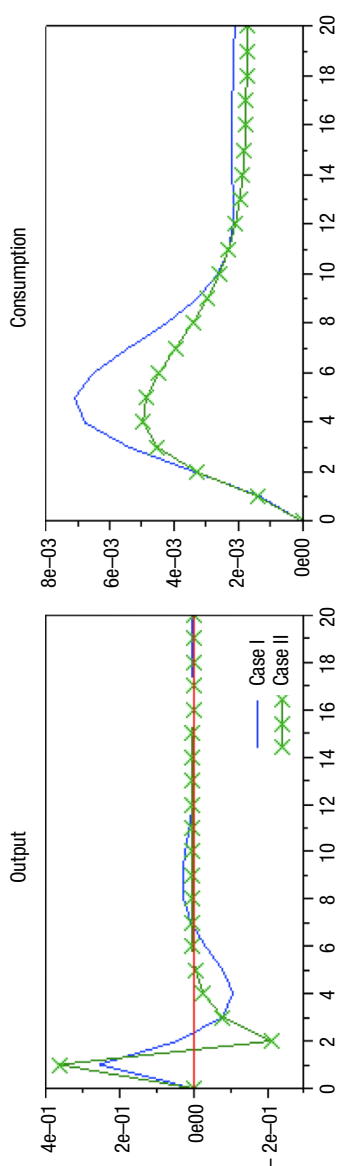
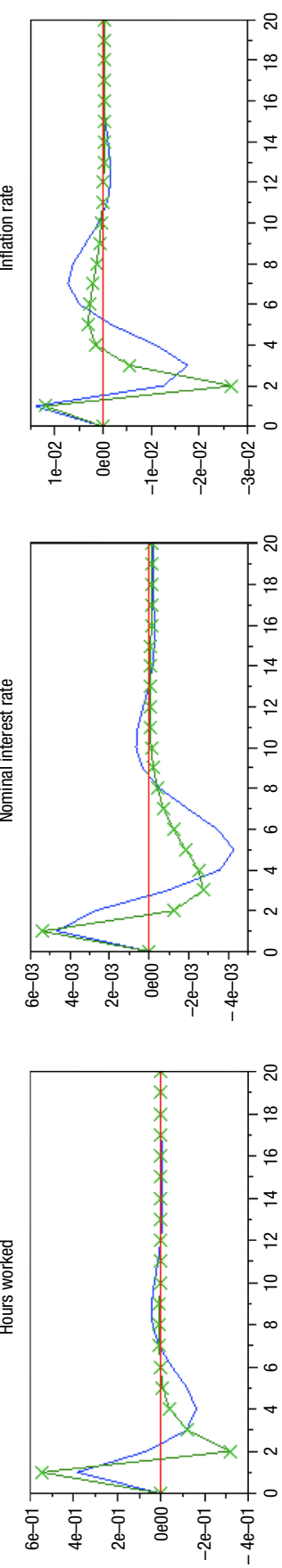

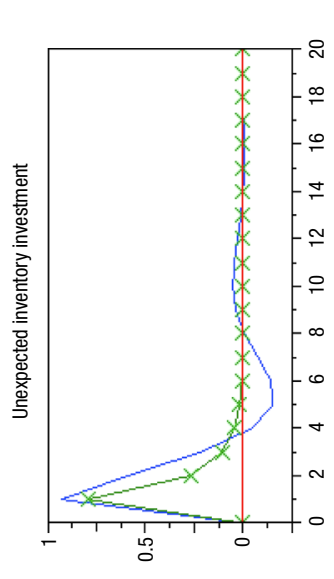

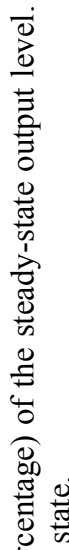

능

的刍焉

흥

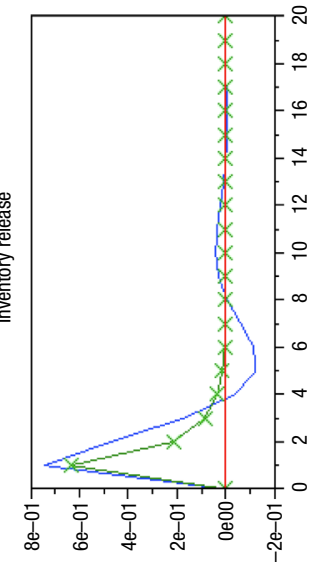

司

$\pi \leftrightarrow$

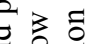

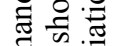

害

政

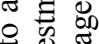

结

政

늉

की

$0 . \exists$

흘

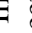

$\dot{0}:$

m.

我春

ह

o

急

$\frac{\pi}{2}$

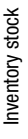

롱

.

.

$\stackrel{\infty}{\Xi}$ 

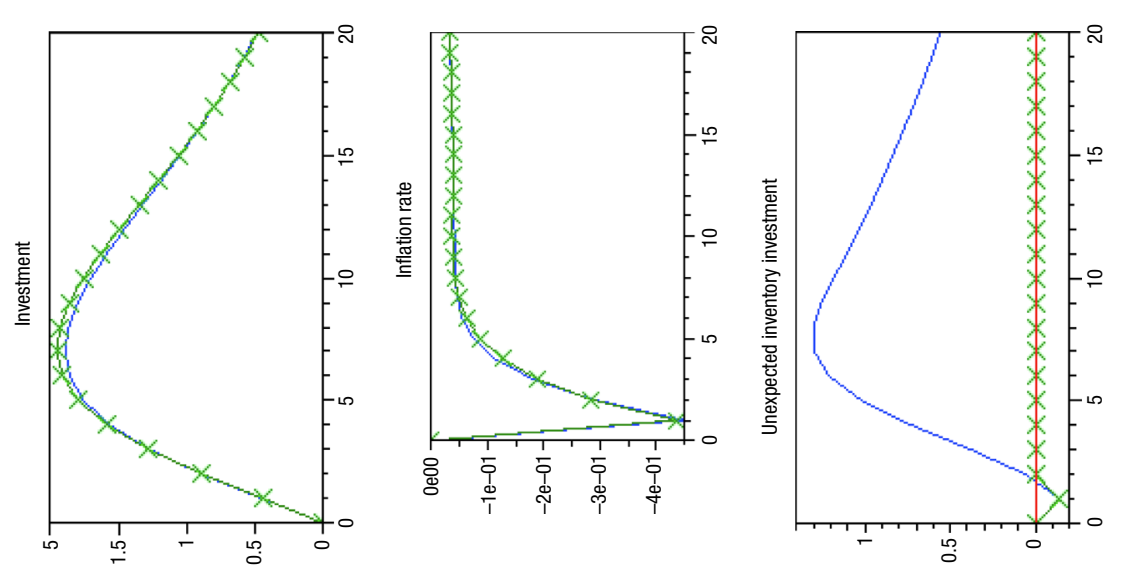

อे
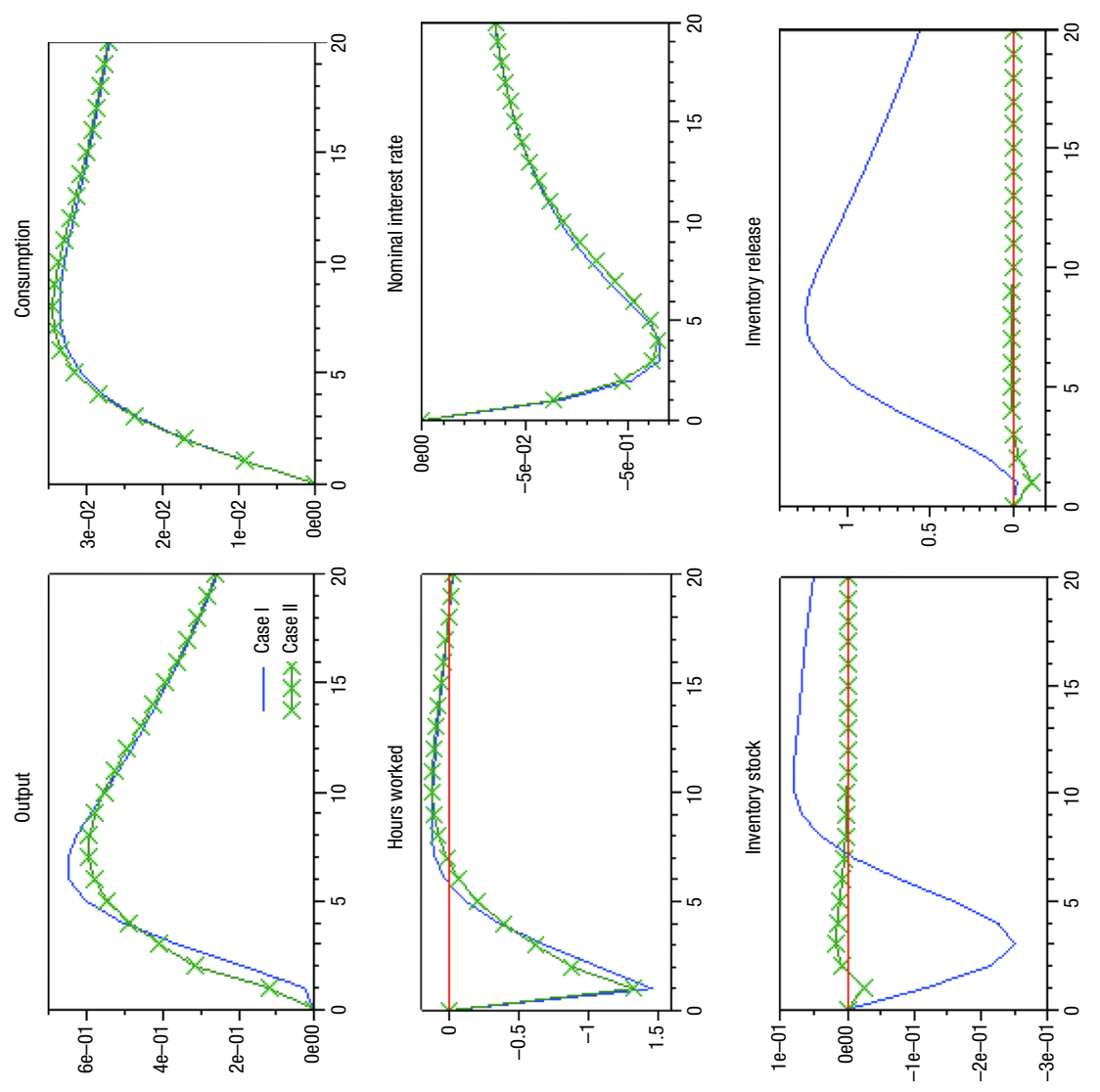

产

䒕

1

ఫ్ఞ

(

㟧

(ิ)

䒿

훙

늠

फิ

究

눙

总

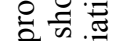

क $\overrightarrow{0}$

용

\&

艺 志

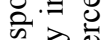

츙

क ज्ञ

言. 统

可

$+80$

임

志

हี

a

$\ddot{F}$

$\frac{\Xi}{0}$

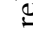

공

อ

.

$\Xi$

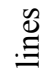

$\stackrel{8}{1}$

若 


\subsection{Inventory cycle}

As shown in the above results of the four simulations, output can have a cyclical movement because of inventory stock. For Case I, Figure 5 depicts the relationship between the change-rate of output and the change of inventory stock, and is a picture of the inventory cycle introduced in Section 2 . The figure shows that output and inventory stock return to their steady state after passing each phase, as explained in Section 2. Thus, our DSGE model can reproduce the inventory cycle that is observed in an actual economy.

(a) Demand prediction shock Change in inventory

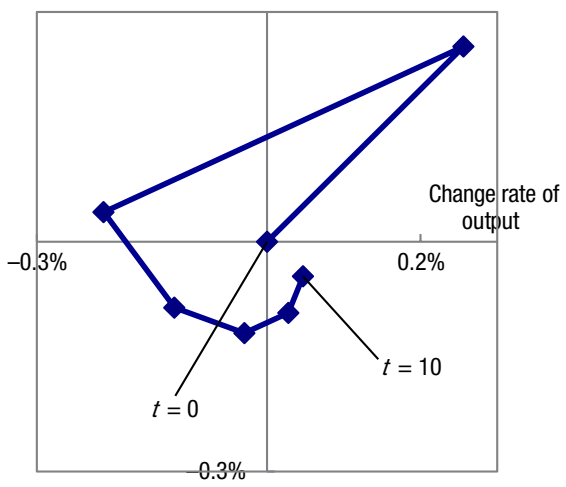

(b) Productivity shock Change in inventory

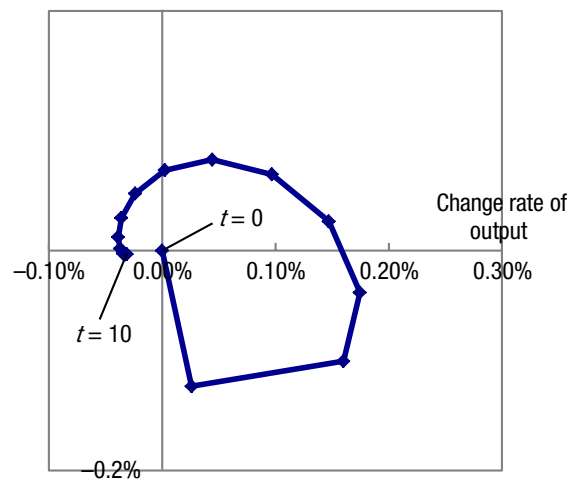

Fig. 5. Simulated inventory cycle in Case I

\section{Discussion}

In this section, we analyze our model in terms of second moments and the sensitivity of some parameters.

\subsection{Second moments}

A production-smoothing model of inventory movement, such as the one discussed here, has two empirical implications. First, it predicts that the volatility of output is smaller than that of sales $\left(Y_{t}^{d}\right)$. Second, inventory investment and output are negatively correlated in a partial equilibrium. However, it has been argued that these two predictions are inconsistent with the data. What about the model proposed in this paper?

To calculate the second moment, we set the standard error of exogenous shocks in our model as follows: $E\left[\left(\varepsilon_{t}^{Y}\right)^{2}\right]=0.594$ (technology shock), $E\left[\left(\varepsilon_{t}^{g}\right)^{2}\right]=0.285$ (fiscal shock), $E\left[\left(\varepsilon_{t}^{I}\right)^{2}\right]=1.0625$ (investment technology shock), and $E\left[\left(\varepsilon_{t}^{R}\right)^{2}\right]=0.0001$ (monetary shock). These are borrowed from Levin et al. (2006). The second moment for demand prediction shock $\sigma_{e} \equiv \sqrt{E\left[\left(\varepsilon_{t}^{n}\right)^{2}\right]}$ is set at 0.5 . Note that the obtained variance is unconditional and is computed by using the formula introduced by DeJong and Dave (2007). 
Table 2 shows matrices in which the diagonal entries are standard deviations and the off-diagonal entries are correlation coefficients for the associated variables. The matrix is made for U.S. data with $\sigma=2$ (Model I-a) as well as $\sigma=0$ and $\sigma_{e}=0$ (Model I-b). Moreover, we also show the matrix for a standard new Keynesian model (Model II) in which inventories and demand uncertainty are not assumed. Note that Model I-b can be interpreted as a DSGE model incorporating inventories in a standard manner.

As shown in Table 2, the actual volatility ratio between output and sales is $1.15=$ $(1.16 / 1.01)$ and that in Model I-a, Model I-b, and Model II is $1.14=(0.57 / 0.50), 1.01=$ $(0.51 / 0.507)$, and 1 (exactly), respectively. Thus, Model I-a can reproduce a ratio close to the actual one ${ }^{10}$. This is because Model I-a can allow uncertainty for demand expectation, which enhances the fluctuation of inventories. Without expectation uncertainty, output fluctuation can be mitigated since inventory serves as a buffer to uncertainty; this is partially confirmed in a decrease in investment volatility, as shown in the result for Model I-b in Table 2. Thus, expectation uncertainty directly affects output, which yields relatively high output volatility.

Model I-a can also avoid a negative correlation between inventory investment $\left(z_{t}-b_{t}\right)$ and output $\left(Y_{t}\right)$, which is confirmed in Table 2. This is because our model has an unexpected inventory change $z_{t}$. If firms produce more goods than they expect, $z_{t}$ increases. This correlation increases with $\sigma$. Furthermore, if $z_{t}$ increases, inventory stock tends to decrease. This may result in a decrease in the inventory release $b_{t}$. Indeed, as shown in Table 2, Model I-a can successfully reproduce the correlation between output and inventory change. On the other hand, the output-inventory correlation in Model I-b and Model II is too low ${ }^{11}$.

Furthermore, a study by Wen (2005) found that inventory is pro-cyclical at low frequencies and counter-cyclical at high frequencies. This observation is found to be consistent with our figure of the inventory cycle (Fig. 5). Figure 5 and the calculated correlation together state that our model can reproduce Wen's (2005) findings.

Thus, incorporating inventories as we do makes a DSGE model more realistic, although there are caveats - for example physical investment volatility implied by the model is low. This should be addressed in future work.

\subsection{Sensitivity analysis}

In this subsection, we look at how changes in the adjustment cost parameters for inventory stock and inventory release $\left(\gamma_{1}\right.$ and $\left.\gamma_{2}\right)$ alter our results. We consider the following six cases: (1) $\gamma_{1}=1, \gamma_{2}=2$; (2) $\gamma_{1}=5, \gamma_{2}=5$; (3) $\gamma_{1}=10, \gamma_{2}=10$; (4) $\gamma_{1}=20, \gamma_{2}=20$; (5) $\gamma_{1}=5, \gamma_{2}=10$ and (6) $\gamma_{1}=10, \gamma_{2}=5$.

\footnotetext{
${ }^{10}$ Note that we can choose $\sigma_{e}$, which is a free parameter, to obtain the exact value of the ratio.

${ }^{11}$ The reason for the positive value in Model I-b is that $z_{t}$ is correlated with output in a general equilibrium setting.
} 
Table 2. Standard deviation and correlation coefficients

\begin{tabular}{|c|c|c|c|c|c|}
\hline & \multicolumn{5}{|c|}{ U.S. Data } \\
\hline & $Y$ & $Y^{d}$ & $C$ & $I$ & $Z-b$ \\
\hline$Y$ & 1.16 & & & & \\
\hline$Y^{d}$ (sales) & 0.94 & 1.01 & & & \\
\hline$C$ & 0.87 & 0.92 & 0.96 & & \\
\hline$I$ & 0.94 & 0.90 & 0.83 & 4.81 & \\
\hline \multirow[t]{3}{*}{$z-b$} & 0.52 & 0.20 & 0.20 & 0.46 & 0.41 \\
\hline & \multicolumn{5}{|c|}{ Model with inventories $(\sigma=2)$} \\
\hline & $Y$ & $Y^{d}$ & $C$ & $I$ & $Z-b$ \\
\hline$Y$ & 0.57 & & & & \\
\hline$Y^{d}$ (sales) & 0.85 & 0.50 & & & \\
\hline$C$ & 0.64 & 0.74 & 0.32 & & \\
\hline$I$ & 0.81 & 0.90 & 0.49 & 1.76 & \\
\hline \multirow[t]{3}{*}{$z-b$} & 0.48 & -0.06 & -0.01 & 0.03 & 0.30 \\
\hline & \multicolumn{5}{|c|}{ Model with inventories $\left(\sigma=0\right.$ and $\left.\sigma_{e}=0\right)$} \\
\hline & $Y$ & $Y^{d}$ & $C$ & $I$ & $Z-b$ \\
\hline$Y$ & 0.51 & & & & \\
\hline$Y^{d}$ (sales) & 0.97 & 0.51 & & & \\
\hline$C$ & 0.74 & 0.75 & 0.33 & & \\
\hline$I$ & 0.90 & 0.91 & 0.50 & 1.80 & \\
\hline \multirow[t]{3}{*}{$z-b$} & 0.15 & -0.10 & 0.01 & 0.01 & 0.12 \\
\hline & \multicolumn{5}{|c|}{ Model without inventories } \\
\hline & $Y$ & $Y^{d}$ & $C$ & $I$ & $Z-b$ \\
\hline$Y$ & 0.51 & & & & \\
\hline$Y^{d}$ (sales) & 1.00 & 0.51 & & & \\
\hline$C$ & 0.75 & 0.75 & 0.33 & & \\
\hline$I$ & 0.91 & 0.91 & 0.50 & 1.80 & \\
\hline$z-b$ & 0.00 & 0.00 & 0.00 & 0.00 & 0.00 \\
\hline
\end{tabular}

Note: Sample perioed of actual data are from 1995:q1 to 2011:q1. Output and sales (=demand) are measured in percentage diviation from detrended data. Detrending is implemented by the HP-filter. $\mathrm{z}-\mathrm{b}$ represents inventory investment, and inventory data is measured in share over detrended-output. Diagonal entries are standard deviations. Off diagonal entries are correlation coefficients.

Figure 6 represents the impulse response of output to the demand prediction shock with $\sigma=2$. The increase in $\gamma_{1}$ slows down the movement of inventory stock, resulting in a prolonged inventory adjustment. On the other hand, the increase in $\gamma_{2}$ leads to an increase in inventory stock. These observations imply that Case (5) may show a prolonged cycle. This is confirmed in Figure 6, which shows that the above six cases yield similar results to those in the previous section. 


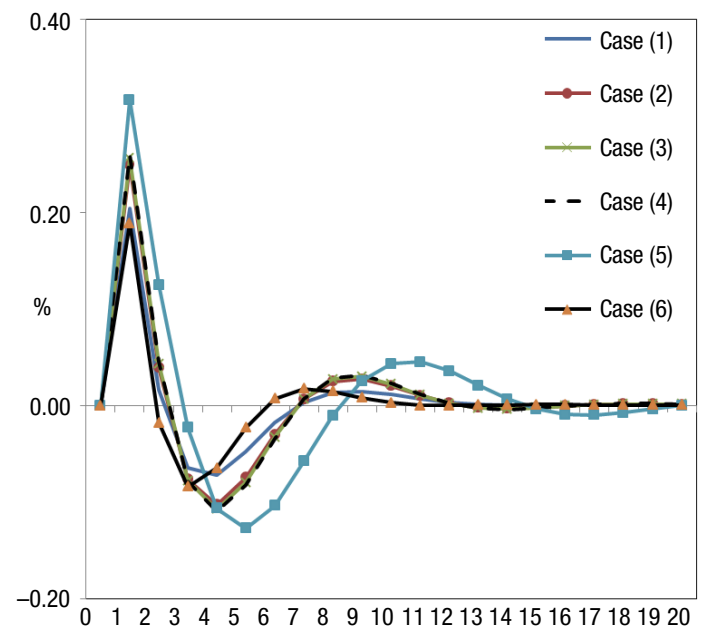

Fig. 6. Sensitivity analysis

Notes: In each case, the figure depicts the impulse response of output to the demand prediction shock, in which we consider the case of $\sigma=2$. Case (1): $\gamma_{1}=1$, $\gamma_{2}=2$; case (2): $\gamma_{1}=5, \gamma_{2}=5$; case (3): $\gamma_{1}=10, \gamma_{2}=10$; case (4): $\gamma_{1}=20, \gamma_{2}=20$; case (5): $\gamma_{1}=5, \gamma_{2}=10$ and case (6): $\gamma_{1}=10, \gamma_{2}=5$.

\section{Concluding remarks}

In this paper, we developed a new Keynesian DSGE model that incorporates inventory stock in a fairly simple manner. It was assumed that firms cannot observe the demand in the current period and must predict it in some framework. Using the model, we simulated how our model economy responds to exogenous shocks. The results showed that given a shock that increases output, the unexpected inventory stocks increase because firms excessively produce goods under the expectation scheme proposed in this model. At the same time, firms decrease output to cut the accumulated inventory stock. Since the reduction of output in a recession is also necessary in our setting, the unexpected inventory stock decreases. This makes firms increase output, and an economic boom is initiated. This cyclical movement continues until the variables return to the steady state. In addition, to check the applicability of our model to an actual economy, we calculate second moments. We confirm that our model can reproduce stylized facts for inventory movements and enhance empirical fit relative to the model without inventory. This implies that incorporating inventory into a DSGE model is an important issue.

\section{References}

Alessandria, G.; Kaboski, J.; Midrigan, V. 2013. Trade wedges, inventories, and international business cycles, Journal of Monetary Economics 60(1): 1-20. http://dx.doi.org/10.1016/j.jmoneco.2012.10.014

Auernheimer, L.; Trupkin, D. R. 2014. The role of inventories and capacity utilization as shock absorbers, Review of Economic Dynamics 17(1): 70-85. http://dx.doi.org/10.1016/j.red.2013.04.003 
Beaudry, P.; Portier, F. 2004a. An exploration into Pigou's theory of cycles, Journal of Monetary Economics 51(6): 1183-1216. http://dx.doi.org/10.1016/j.jmoneco.2003.10.003

Beaudry, P.; Portier, F. 2004b. When can changes in expectations cause business cycle fluctuations in neo-classical settings?, NBER Working Paper Series 10776.

Bils, M.; Khan, J. M. 2000. What inventory behavior tells us about business cycles, American Economic Review 90(3): 458-481. http://dx.doi.org/10.1257/aer.90.3.458

Blanchard, O. 1983. The production and inventory behavior of the American automobile industry, Journal of Political Economy 91(3): 365-400. http://dx.doi.org/10.1086/261154

Blinder, A. S. 1981. Retail inventory behavior and business fluctuations, Brookings Papers on Economic Activity 2: 443-505. http://dx.doi.org/10.2307/2534345

Blinder, A. S. 1986. Can the production smoothing model of inventory behavior be saved?, Quarterly Journal of Economics 101(3): 431-453. http://dx.doi.org/10.2307/1885691

Blinder, A. S.; Maccini, L. 1991. Taking stock: a critical assessment of recent research on inventories, Journal of Economic Perspectives 5(1): 73-96. http://dx.doi.org/10.1257/jep.5.1.73

Calvo, G. 1983. Staggered price setting in a utility-maximizing framework, Journal of Monetary Economics 12(3): 383-398. http://dx.doi.org/10.1016/0304-3932(83)90060-0

Caplin, A. S. 1985. The variability of aggregate demand with (S,s) inventory policies, Econometrica 53: 1395-1409. http://dx.doi.org/10.2307/1913214

Christiano, L; Eichenbaum, M.; Evans, C. 2005. Nominal rigidities and the dynamic effects of a shock to monetary policy, Journal of Political Economy 113(1): 1-45.

http://dx.doi.org/10.1086/426038

Christiano, L. 1988. Why does inventory investment fluctuate so much?, Journal of Monetary Economics 21(2-3): 247-280. http://dx.doi.org/10.1086/426038

DeJong, D. N.; Dave, C. 2007. Structural macroeconomics. Princeton, NJ: Princeton University Press.

Fisher, J. D. M.; Hornstein, A. 2000. (S,s) inventory policies in general equilibrium, Review of Economic Studies 67(1): 117-145. http://dx.doi.org/10.1111/1467-937X.00124

Khan, A.; Thomas, J. K. 2007a. Explaining inventories: a business cycle assessment of the stockout avoidance and (S,s) motives, Macroeconomic Dynamics 11(5): 638-664.

http://dx.doi.org/10.1017/S1365100507060269

Khan, A.; Thomas, J. K. 2007b. Inventories and the business cycle: an equilibrium analysis of (S,s) policies, American Economic Review 97(4): 1165-1188.

http://dx.doi.org/10.1257/aer.97.4.1165

Khan, J. 1987. Inventories and the volatility of production, American Economic Review 77(4): 667-679.

Kydland, F. E.; Prescott, E. C. 1982. Time to build and aggregate fluctuations, Econometrica 50(6): 1345-1370. http://dx.doi.org/10.2307/1913386

Levin, A.; Onatski, J.; Williams; Williams, N. 2006. Monetary policy under uncertainty in microfounded macroeconometric models, NBER Macroeconomics Annual 20: 229-287.

Lubik, T. A.; Teo, W. L. 2012. Inventories, inflation dynamics and the New Keynesian Phillips curve, European Economic Review 56(3): 327-346.

http://dx.doi.org/10.1016/j.euroecorev.2011.10.002

Nutahara, K. 2010. Internal and external habits and news-driven business cycles, Economics Letters 107(2): 300-303. http://dx.doi.org/10.1016/j.econlet.2010.02.018

Ramey, V. 1991. Nonconvex costs and the behavior of inventories, Journal of Political Economy 99(2): 306-334. http://dx.doi.org/10.1086/261752 
Smets, F.; Wouters, R. 2007. Shocks and frictions in US business cycles: a Bayesian DSGE approach, American Economic Review 97(3): 586-606. http://dx.doi.org/10.1257/aer.97.3.586

Stokey, N. L.; Lucas, R. E. 1989. Recursive methods in economic dynamics. Cambridge, London: Harvard University Press.

Teo, W. L. 2011. Inventories and optimal monetary policy in a small open economy, Journal of International Money and Finance 30(8): 1719-1748.

http://dx.doi.org/10.1016/j.jimonfin.2011.09.003

Wang, P.; Wen, Y.; Xu, Z. 2014. What inventories tell us about aggregate fluctuations - a tractable approach to (S,s) Policies, Federal Reserve Bank of St. Louis Working Paper Series 2012-059B.

Wen, Y. 2005. Understanding the inventory cycle, Journal of Monetary Economics 52(8): 15331555. http://dx.doi.org/10.1016/j.jmoneco.2004.10.009

Zeira, J. 1994. Informational cycles, Review of Economic Studies 61(1): 31-44.

http://dx.doi.org/10.2307/2297875

Kenichi TAMEGAWA. He is Associate Professor at Yamagata University (Japan). His main research interests include business cycle theory, regional science, and marketing science. He has papers more than 20 in national and international journals. 